\title{
Estimating sediment delivery ratio by stream slope and relief ratio
}

\author{
Kieu Anh Nguyen ${ }^{1}$ and Walter Chen ${ }^{1, *}$ \\ ${ }^{1}$ Department of Civil Engineering, National Taipei University of Technology, Taipei, Taiwan
}

\begin{abstract}
Nowadays, the storage capacity of a reservoir reduced by sediment deposition is a concern of many countries in the world. Therefore, understanding the soil erosion and transportation process is a significant matter, which helps to manage and prevent sediments entering the reservoir. The main objective of this study is to examine the sediments reaching the outlet of a basin by empirical sediment delivery ratio (SDR) equations and the gross soil erosion. The Shihmen reservoir watershed is used as the study area. Because steep terrain is a characteristic feature of the study area, two SDR models that depend on the slope of the mainstream channel and the relief-length ratio of the watershed are chosen. It is found that the Maner (1958) model, which uses the relief-length ratio, is the better model of the two. We believe that this empirical research improves our understanding of the sediment delivery process occurring in the study area.
\end{abstract}

\section{Introduction}

In recent years, soil erosion has become one of the most serious environmental issues in the world due to climate change. The determination of the amount of loose sediments in an area such as a watershed is an important first step to understand the problem.

Not all of the sediments will reach river channels or reservoirs. Sediment delivery involves soil erosion, transportation, and deposition. Sediment delivery ratio (SDR) is defined as the percentage of sediment yield to the total amount of soil erosion occurred in the erosion process. It can be written as follows:

$$
\mathrm{SY}=\mathrm{SDR} \times \mathrm{SE}
$$

where

$\mathrm{SDR}=$ sediment delivery ratio

$\mathrm{SY}=$ sediment yield

$\mathrm{SE}=$ total soil erosion

SDR is controlled by many factors such as land use, catchment area, relief-length ratio, soil texture, transportation process, and slope gradient of the mainstream channel. Many studies have examined the relationships between the SDR and the factors above. However, most of the studies focused on the drainage area because the size of the area was easy to determine. We believe that there are other parameters more suitable for the empirical determination of SDR. Therefore, the purpose of this study is to use the slope of the mainstream channel and the relief-length ratio of the watershed to compute SDR, and to compare the results of the study area.

\section{Study area and previous work}

Shihmen reservoir watershed is located in the northern part of Taiwan and mostly in the Taoyuan City and the
Hsinchu County (Fig. 1). The watershed is mostly covered by forest with an area of $759.53 \mathrm{~km}^{2}$, and the elevation ranges from $220 \mathrm{~m}$ to $3527 \mathrm{~m}$.

Shihmen reservoir watershed receives an average of $2200 \mathrm{~mm}$ to $2800 \mathrm{~mm}$ of precipitation annually, delivered by typhoons and rainstorms typically from May to August every year. Because of the location of Taiwan, tropical storms frequently cause flooding, landslides, and soil erosion.

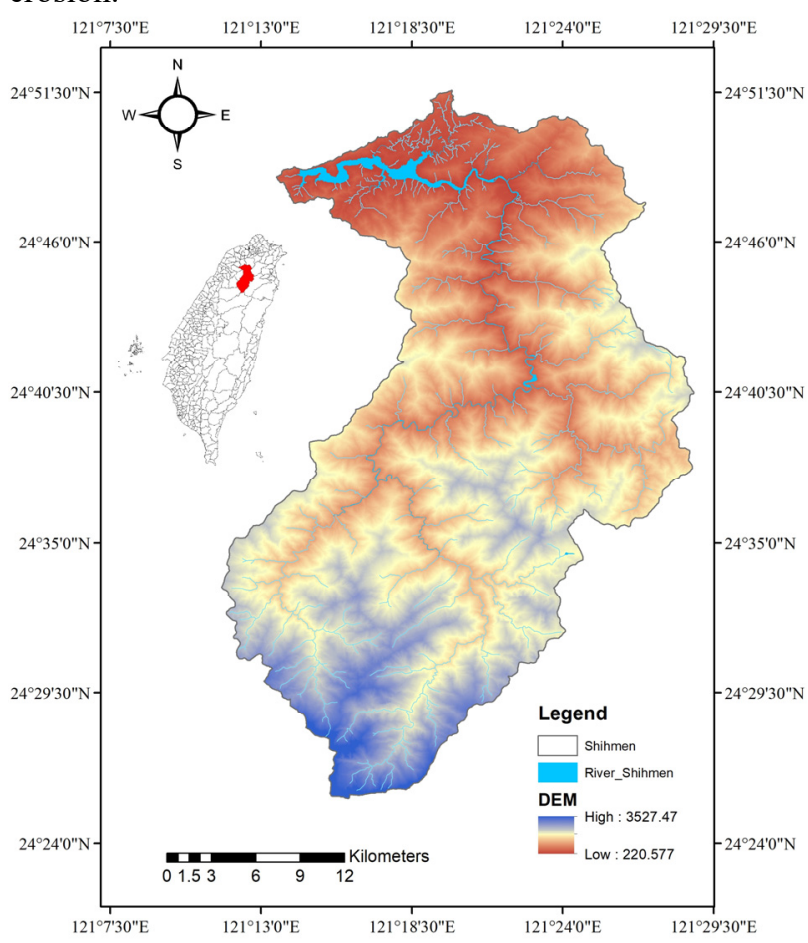

Fig. 1. Study area of the Shihmen reservoir watershed.

Previously, we have used eight empirical equations to evaluate SDR [1]. The independent variables include the

* Corresponding author: waltchen@ntut.edu.tw 
drainage area, the runoff of the basin, the slope of the mainstream channel, and the relief-length ratio (Fig. 2). Among them, the relief-length ratio gives the best result, while the slope of the mainstream channel gives the worst estimate of SDR. However, since both models use similar topographic parameters, the question remains why such a big difference exists. In order to clarify this problem, we further compare the two models in this study.

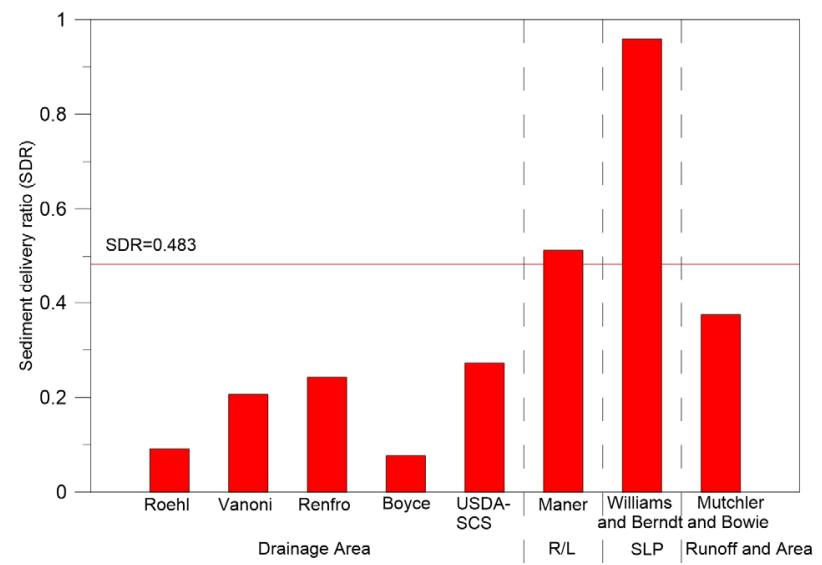

Fig. 2. SDRs of the Shihmen reservoir watershed estimated by eight empirical equations.

\section{Research method}

The two empirical models are described below.

\subsection{SLP}

Williams and Berndt (1977) derived the sediment delivery ratio for the catchment basin of Brushy creek of Texas [2] that connected SDR to the geomorphological and sediment-logical feature of the catchment. The equation is written as follows (Fig. 3a):

$$
\mathrm{SDR}=0.627 \times S L P^{0.403}
$$

where

SLP $=$ percent slope of mainstream channel

The mainstream is defined as the stream of the highest stream order. The slope of the mainstream depends on the stream profile, and is defined as the horizontal distance along the mainstream channel divided by the elevation difference between the two end points of the mainstream.

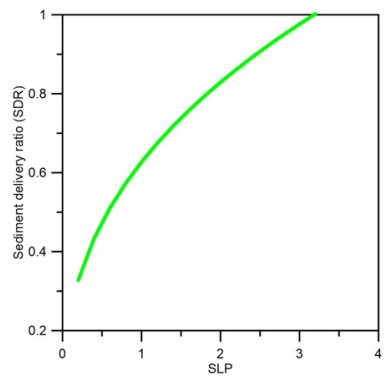

(a)

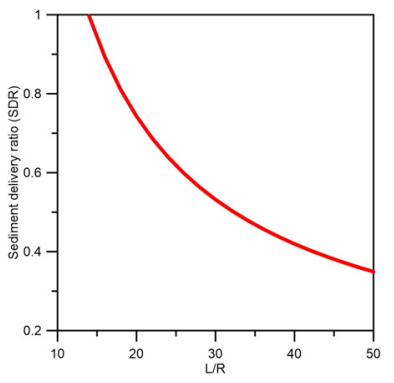

(b)
Fig. 3. Relationships between SDR and (a) SLP, and (b) R/L

For the study area of the Shihmen reservoir watershed, the mainstream is shown in Fig. 4. We use the ArcMap software and the Flow functions to determine the length of the mainstream. The result shows that the mainstream length of the Shihmen reservoir watershed is $105.309 \mathrm{~km}$, and the difference in elevations is $3,023 \mathrm{~m}$.

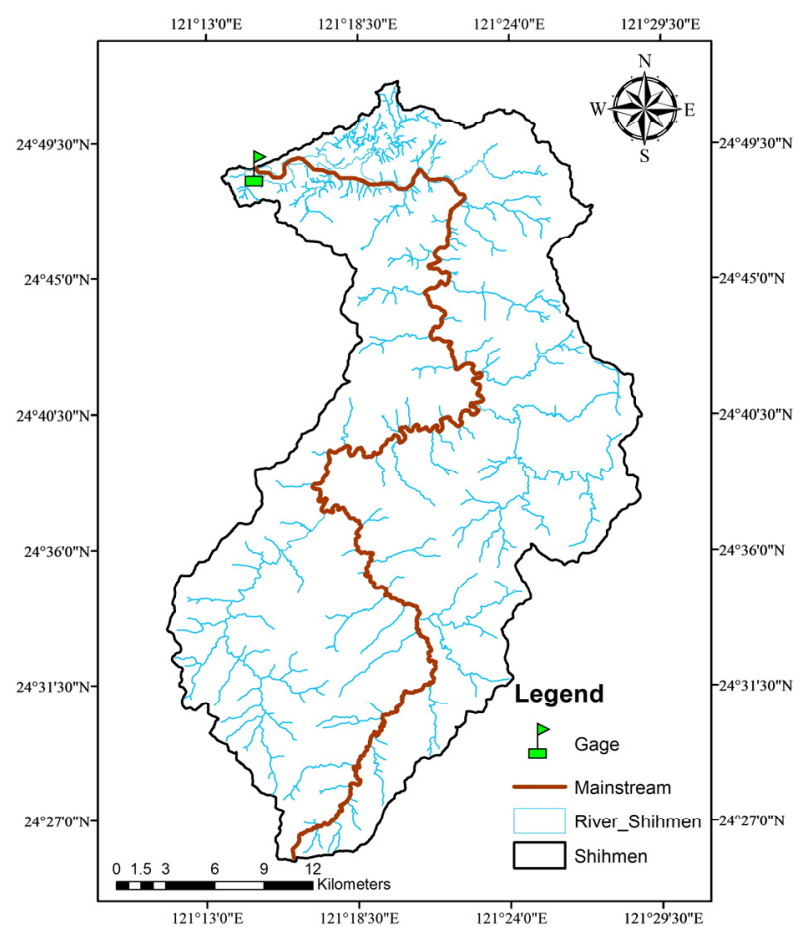

Fig. 4. Mainstream of the Shihmen reservoir watershed.

\subsection{R/L}

Relief-length ratio is the ratio between the relief of the basin $(\mathrm{R})$ and the length of the basin (L). Contradictory to the SLP factor, the inverse of the relief-length ratio is inversely related to the sediment delivery ratio (Fig. 3b).

The relief-length ratio provides the general steepness of a drainage basin and the power of erosion process along the slopes of the basin. Schumm [3] illustrated that the soil loss per unit area of a basin was linked to the relief-length ratio, and recommended that a close relationship might exist between the relief-length ratio and the hydrological characteristics of the basin. In this paper, the Maner equation is used [4]:

$$
\operatorname{logSDR}(\%)=2.943-0.82 \operatorname{colog} \frac{R}{L}
$$

where $\mathrm{R}$ is the relief of the watershed. It is defined as the difference between the average elevation at main headwaters and the elevation at basin outlet. L is the maximum length of the watershed parallel to the mainstream channel. The Shihmen reservoir watershed is divided into three main drainage sub-basins which contain three headwaters, as shown in Fig. 5 (points A, B, and C). The relief $\mathrm{R}$ is calculated to be $1513 \mathrm{~m}$, and the length $\mathrm{L}$ is found to be $48304.87 \mathrm{~m}$.

\section{Results}

As mentioned earlier, Fig. 2 showed the comparison of SDRs estimated by eight empirical equations for the 
Shihmen reservoir watershed, and the figure was used to examine the relative errors of different equations. Since the SDR of the Shihmen reservoir watershed is 0.483 (from dredging data), it can be seen from the figure that the relief-length ratio of Maner (1958) yields a much more accurate estimate of the SDR than the SLP of William and Berndt (1972) in the Shihmen reservoir watershed.

Table 1 further compares $\mathrm{R} / \mathrm{L}$ and SLP. The table illustrates the similarity and difference between the two parameters. The $\mathrm{R} / \mathrm{L}$ model reflects the variation of elevation with respect to distance along the length of the watershed. The elevation difference between the headwaters of the main tributaries and the outlet is used as the average elevation difference of the basin. On the other hand, in the SLP model, the elevation difference between the two end points of the mainstream divided by the stream length represents the slope of the mainstream, not necessarily the slope of the terrain of the watershed. To illustrate the difference, the profiles along the mainstream and the basin length are shown in Fig. 6 and Fig. 7, respectively.

The topography of the Shihmen reservoir watershed is characterized by steep slopes and fast moving flows. Although the mainstream of the Shihmen reservoir watershed is very long and tortuous, the SLP model still over estimates the SDR.

\section{Conclusions}

In this study, we compared and contrasted two very similar empirical equations used in the assessment of SDR. It is found that the relief-length ratio equation from Maner (1958) is better than the SLP equation. In fact, the Maner (1958) equation is the best equations among the eight empirical equations compared in a related study [1]. It is the best choice for the Shihmen reservoir watershed.

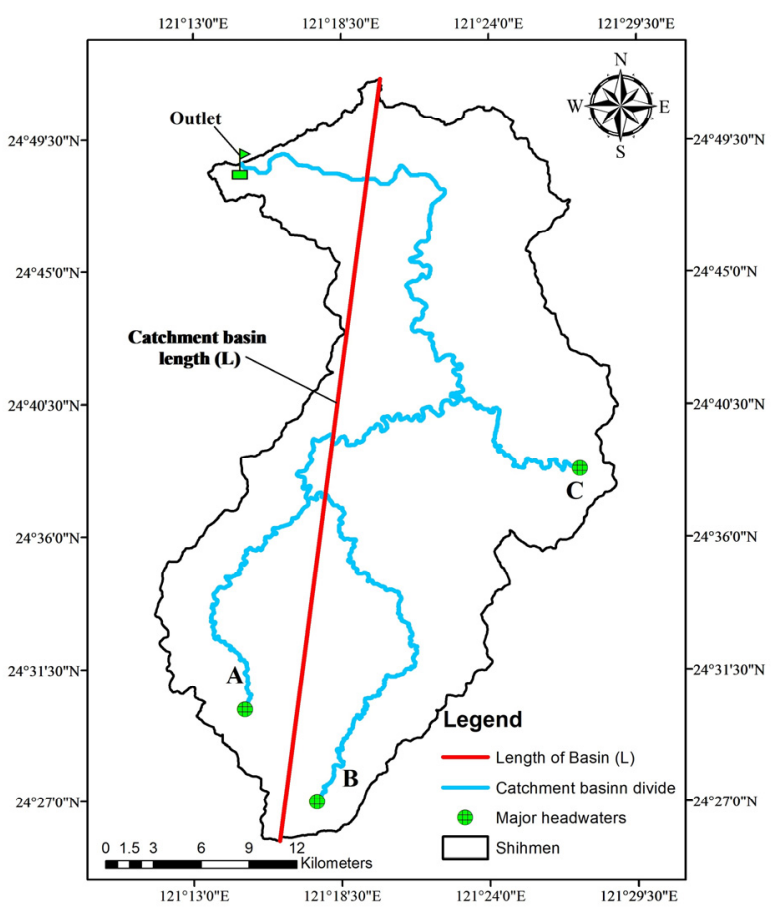

Fig. 5. Length and headwaters of the Shihmen reservoir watershed.
Table 1. Comparison between $\mathrm{R} / \mathrm{L}$ and SLP.

\begin{tabular}{|c|c|c|}
\hline $\begin{array}{c}\text { Elevation } \\
\text { parameters }\end{array}$ & $\begin{array}{c}\text { Relief-length ratio } \\
\text { (R/L) } \\
\text { of heage elevation } \\
\text { Elevation of outlet }\end{array}$ & $\begin{array}{c}\text { Maximum elevation } \\
\text { of mainstream } \\
\text { Minimum elevation } \\
\text { of mainstream }\end{array}$ \\
\hline Length parameter & Basin length & Mainstream length \\
\hline Slope parameter & Slope of basin & $\begin{array}{c}\text { Slope of } \\
\text { mainstream }\end{array}$ \\
\hline
\end{tabular}

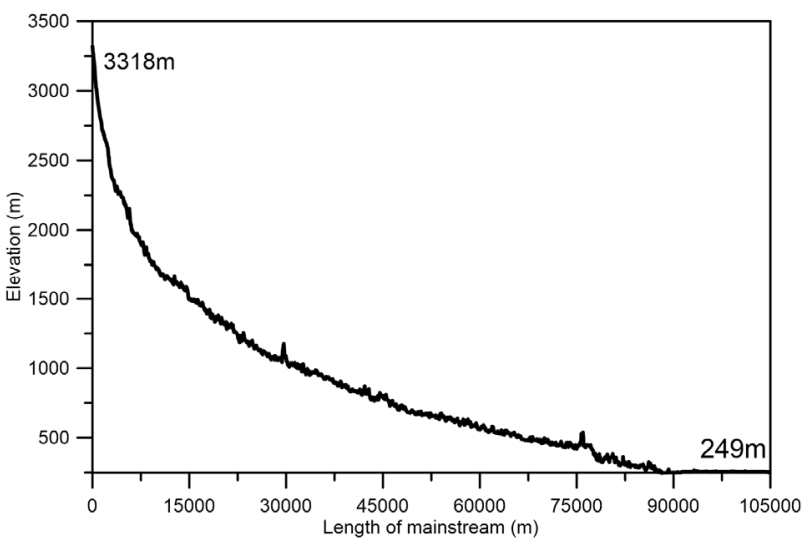

Fig. 6. Profile along the mainstream channel.

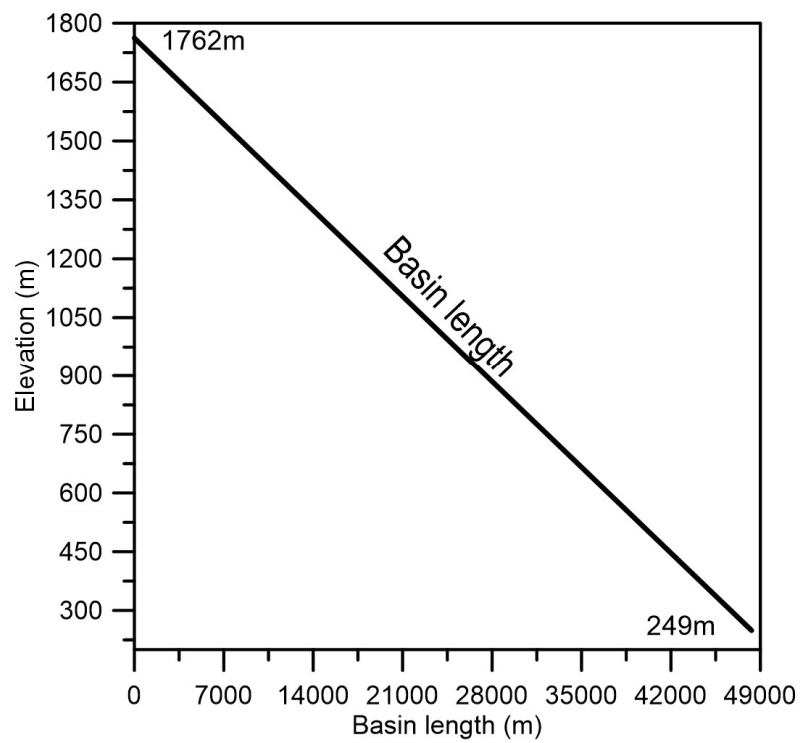

Fig. 7. Profile along the basin length.

This study was partially supported by the National Taipei University of Technology-King Mongkut's Institute of Technology Ladkrabang Joint Research Program (grant number NTUT-KMITL-106-01 and NTUT-KMITL-107-02) and the Ministry of Science and Technology (Taiwan) Research Project (grant number MOST 106-2119-M-027-004).

\section{References}

1. K. A. Nguyen, W. Chen, Comparison of empirical SDR equations. In: International Symposium on Remote Sensing 2018, Pyeongchang, Korea (2018)

2. J. R. Williams, H. D. Berndt, Sediment yield computed with universal equation. Journal 
Hydraulics Division Proceedings, ASCE, 98(HY12), pp. 2087-2097 (1972)

3. S. A. Schumm, Evolution of drainage systems and slopes in badlands at Perth Amboy, New Jersey. Geological Society of America Bulletin, 67(5), pp. 597-646 (1956)

4. S. B. Maner, Factors affecting sediment delivery rates in the Red Hills physiographic area. Transactions, American Geophysical Union, 39(4), pp. 669-675 (1958) 